\title{
Valores emergentes del pretérito pluscuamperfecto en el español andino hablado en Chinchero (Cuzco) $)^{1}$
}

\author{
Ana Isabel García Tesoro \\ Universidad de Tokio
}

\begin{abstract}
Resumen
El presente trabajo tiene como objeto describir y explicar los usos del pretérito pluscuamperfecto en español andino. Para ello, hemos analizado 15 entrevistas orales semidirigidas realizadas en el distrito de Chinchero (Cuzco, Perú) en 2011 y 2012 a hablantes bilingües quechua-español. El análisis del corpus muestra que los usos del pluscuamperfecto no siempre parecen coincidir con los valores atribuidos normalmente a este tiempo verbal, esto es, indicar una acción pasada anterior a otra también pasada, sino que están relacionados con la validación de la información y se emplea como un reportativo o evidencial para narrar acontecimientos no vividos, normalmente históricos o legendarios, eventos cuya veracidad el hablante no puede asegurar o evalúa como no fiable, así como para expresar miratividad o sorpresa ante la información recibida o los hechos ocurridos.
\end{abstract}

* Para correspondencia, dirigirse a: Ana Isabel García Tesoro (anaigarcia@gmail.com), Facultad de Artes y Ciencias 3-8-1 Komaba, Meguro-ku, Tokio (153-8902).

1 Esta investigación está financiada por Japanese Society for the Promotion of Science, Grant in Aid for Young Scientists (B) $n^{\circ}$ 24720182, y se ha desarrollado parcialmente en el marco del proyecto "El español en contacto con otras lenguas: variación y cambio lingüístico", Ministerio de Economía y Competitividad de España (FFI2012-31702). 
Palabras clave: lingüística de contacto, español andino, cambio inducido por contacto, gramaticalización.

\title{
Emerging values of Pluperfect in Andean Spanish \\ (Chinchero, Cusco)
}

\begin{abstract}
This research aims to describe and explain the values of pluscuamperfect (past perfect) tense in Andean Spanish. To achieve our purpose that, we analysed 15 semi-structured oral interviews of Quechua-Spanish bilingual speakers, in the district of Chinchero (Cuzco, Peru), which were done in 2011 and 2012. The analysis of the corpus shows that the use of pluscuamperfect tense does not coincide with the usual one, that is indicate a past event previous to another past event. Otherwise it seems to be related with validation of the information and reportative or evidentiality values and is used to narrate events not lived and legends, events whose veracity is not reliable, and to express mirativity facing received information or occurred events.
\end{abstract}

Keywords: Contact Linguistics, Andean Spanish, contact induced change, grammaticalization.

Recibido: 11/03/15 Aceptado: 20/09/15

\section{INTRODUCCIÓN}

El español andino, castellano andino o español de los Andes son conceptos ampliamente utilizados en la bibliografía especializada para referirse a la variedad de español en contacto con el quechua hablada en gran parte de la Sierra Andina (Escobar 2011, García Tesoro 2013, Haboud 1998, Klee y Lynch 2009, Merma Molina 2008, Pfänder 2009, Zavala 1996, entre otros). Entre los diversos fenómenos que lo caracterizan destaca el empleo de los tiempos de pasado, además de con sus valores canónicos, con usos innovadores relacionados con la evidencialidad y el carácter sorpresivo de la información transmitida que se manifiestan con variaciones en distintas regiones o países mediante el uso del pretérito indefinido (comi), el perfecto (he comido) o el pluscuamperfecto (habia comido) (Blestel 2011, Escobar 
1997, Granda 1994, Hintz 2007, Klee y Ocampo 1995, Pfänder y Palacios 2013, Speranza 2010). La adopción de estos valores modalizadores ha sido puesta en relación con la situación de contacto con el quechua, en cuyo sistema verbal la miratividad (o admiratividad en otros trabajos), la evidencialidad o la codificación de la fuente de la información, así como la veracidad subjetiva y la responsabilidad que el hablante asume respecto del mensaje que transmite, son parámetros fundamentales ${ }^{2}$.

El presente trabajo tendrá como objeto presentar el análisis de los usos del pretérito pluscuamperfecto en narraciones de un corpus de entrevistas orales realizadas a informantes bilingües quechua-español recogido en el distrito de Chinchero (Cuzco). El análisis del corpus muestra que los usos del pluscuamperfecto no siempre parecen coincidir con los valores atribuidos normalmente a este tiempo verbal, esto es, indicar una acción pasada anterior a otra también pasada, sino que se usaría también como un reportativo o evidencial para narrar acontecimientos no vividos, normalmente históricos o legendarios, eventos cuya veracidad el hablante no puede asegurar o evalúa como no fiable, así como para expresar miratividad o sorpresa ante la información recibida o los hechos ocurridos. De esta forma lo situarían en un estado más avanzado en el proceso de gramaticalización de las formas de perfecto hacia la evidencialidad apuntadas por Aikhenvald (2004), Bermúdez (2005) o Soto y Hasler (2013), y en la perspectiva de la subjetivación planteada por Traugott $(1989,1995)$, ya que la adquisición de estos nuevos valores del pluscuamperfecto se fundamenta en la necesidad de expresar valores gramaticalizados en el quechua como la miratividad y se orienta hacia la subjetivación en el discurso oral, proceso que ya ha sido apuntado para otros fenómenos de variación en español andino (Palacios y García 2014). Proponemos en este estudio, por tanto, que el contacto con el quechua se constituye como disparador del cambio analizado, pero no como un mero trasvase o calco semántico, sino como un proceso de convergencia lingüística en el que los hablantes perciben similitudes, siguiendo a Jarvis y Pavlenko (2008) y Palacios y Pfänder (2014), y las formas lingüísticas de las dos lenguas de contacto se acercan en un proceso de cambio semántico. Dicho proceso ha desembocado en la emergencia de valores evidenciales y

\footnotetext{
2 En ese sentido, coincidimos con la postura de Dendale y Tasmowski (2001) y entendemos la evidencialidad en un sentido amplio ligada a la modalidad epistémica, como un modo de expresar la evaluación subjetiva que el hablante hace de la fuente de la información así como de la veracidad de un enunciado. Entendemos la miratividad también relacionada con la modalidad, como la categoría que especifica la probabilidad de veracidad de un enunciado, y con la evidencialidad.
} 
mirativos en el pluscuamperfecto de dicha variedad. La asunción de estos valores modales en el pluscuamperfecto ha sido posible porque este tiempo en español ya presenta valores que permiten una lectura epistémica (Soto y Olguín 2010), e igualmente ha sido puesto de manifiesto para otros tiempos verbales compuestos del español (Jara 2011, Soto y Hasler 2013). El cambio por contacto en este caso permite entonces la ampliación de valores modales relacionados con la evidencialidad y la miratividad en el pluscuamperfecto en español. A pesar de la distancia entre español y quechua, en nuestra opinión, lo que cuenta no es la semejanza tipológica sino la semejanza percibida, la percepción que el hablante tiene de su lengua, de la lengua de contacto y de los recursos lingüísticos de ambas lenguas.

\section{EL PRETÉRITO PLUSCUAMPERFECTO EN ESPAÑOL ANDINO: ¿UN CALCO DEL QUECHUA?}

Tradicionalmente, el valor que se atribuye al pluscuamperfecto es el de remitir a una acción pasada anterior a una primera acción que normalmente también es pasada (1a-f), aunque no necesariamente (1g-h), como se puede apreciar en los ejemplos que siguen (tomados de Cartagena 1999: 2952):

(1) a. En la tarde del domingo contesté las dos cartas que había recibido el domingo.

b. Bien se echaba de ver que había pasado por alli un ejército.

c. Creería que le habíamos perdido aposta.

d. Yo no hubiera querido que tú supieras nunca que yo había tenido que perdonar.

e. Y perdona que te haya dicho todo esto que me había propuesto callar siempre.

f. Nunca me habría imaginado que la política ya había dejado de interesarle.

g. IImagínate que a mediodía el muy perezoso todavia no se había levantado!

h. Conste que nunca me habías pedido ayuda.

Asimismo, como todos los tiempos compuestos de <haber+participio $>$, conforme a su significado original implica perfección, esto es, que los hechos ya se han realizado dentro del ámbito temporal referido; en el caso 
del pluscuamperfecto puede tener una lectura aspectual perfecta, esto es, aquella en la que se focaliza el estado de cosas posterior al evento (2a) o aorística, en la que se pasa a focalizar el evento anterior (2b) (ejemplos tomados de García Fernández 2008: 365):

a. A las tres ya había escrito la carta.

b. Había escrito la carta a las tres.

Por otro lado, es bien conocido que en variantes de español en contacto con el quechua ${ }^{3}$ se recogen otros usos que poco tienen que ver con la remisión a hechos en un punto determinado del pasado, sino más bien con valores evidenciales (3a) o de carácter sorpresivo ante la información (3b) y que son considerados como cambios que están motivados por el contacto con el quechua. Véanse como ejemplos los siguientes citados en Blestel (2011: 72-73):

a. Por el lado de Chávez, informes de inteligencia venezolanas dicen que poseen pruebas de las relaciones del Gobierno de Uribe con las desmovilizadas Autodefensas Unidas de Colombia (AUC). Y la carta de Correa es que, según las investigaciones de los ecuatorianos, la incursión, que en un principio Colombia dijo que había sido que fue una persecución en caliente, fue planeada y con ayuda de alguna "potencia extranjera", desde la base de Manta (Ecuador), operada por EE. UU. en virtud de un convenio que no va a ser renovado (El Diario, Ecuador).

b. Al inicio teníamos un poco de miedo porque las personas que trabajaban en las refinerías eran mayores. En el lugar no habia operadores mujeres tanto asi que en el área de procesos no habia baños para mujeres. En ese sentido también, el otro día estaba abriendo una válvula, llega un señor de Transredes, me ve de espaldas y cuando me ve de frente me dice: "ay, habias sido mujer". Y claro, como si una mujer no podría hacer lo que hacen los hombres. Hemos demostrado que las mujeres también pueden (Bolivia).

3 También en variantes de contacto con aimara y guaraní, véase Blestel 2011, Granda 1994 o Palacios 2008. 
Diversos autores señalan efectivamente usos innovadores para este tiempo verbal en español andino (Blestel 2011, Calvo 2008, Escobar 1997, Godenzzi 1996, Granda 1994, Hintz 2007, Klee y Ocampo 1995, Mendoza 2008, Pfänder y Palacios 2013, Speranza 2010), especialmente se informa de valores evidenciales que enfatizan que los hechos narrados no fueron experimentados o vistos en primera persona por el hablante, sino que está reportando una información que procede bien de otra persona o que se refiere a hechos míticos que se remontan muchos años atrás. Así, Granda (1994) señala para el español peruano que el pluscuamperfecto se usa con estos valores en oposición al pretérito perfecto, que es preferido para narrar hechos como pasado no marcado. Asimismo, se informa sobre valores mirativos que comunican sorpresa por parte del narrador en varios estudios (Calvo 2008, Granda 1994), esto es, que toma conciencia de una información que desconocía y acaba de descubrir o que no había tenido en cuenta (véase el ejemplo 3b). Calvo (2008) incluye este segundo valor dentro del campo más amplio de la evidencialidad y no lo interpreta como un valor diferente del descrito anteriormente ${ }^{4}$.

Todos los investigadores coinciden en poner en relación este fenómeno con la influencia del quechua, lengua en la que los elementos validadores o evidenciales, es decir, aquellos que marcan el origen o la fuente que han facilitado la información que conoce y transmite el hablante, y sobre todo la veracidad que el hablante confiere a dicha información, son fundamentales y están gramaticalizados en dos niveles: en el sistema verbal mediante el sufijo de pasado $-\tilde{n} a q$ o $-s q a$, que señala el pasado no experimentado y codifica valores evidenciales y mirativos; y mediante el uso de una serie de sufijos validadores cuya presencia es categórica, como $-m i /-n$ que indica que el hablante conoce de primera mano los hechos o confiere valor de veracidad a los mismos (Faller 2003, 2007), el sufijo -ši $/-s$ que refiere informaciones reportadas o recibidas de manera indirecta por el hablante, o $-\check{c} i$ que se usa para marcar informaciones inferidas conjeturalmente a partir de otras (Cerrón Palomino 1987, Cusihuamán 1976), en fin, de evaluación del grado de veracidad de la información transmitida y de determinación de la fuente de información como directa y confiable o no, según el contexto. De esta forma, los usos innovadores del pluscuamperfecto han sido interpretados como un calco funcional o semántico, bien de los sufijos oracionales $-m i /-n$ de conocimiento directo y $-s ̌ i /-s$ de conocimiento inferido o reportado

\footnotetext{
4 Interpretación que coincide con DeLancey (2001) o Palmer (1986), entre otros, que consideran la miratividad como una parte de la evidencialidad, ya que igualmente no existe control por parte del hablante sobre la información.
} 
(Escobar 1997), bien del verbal -sqa, cuyo uso es optativo frente a otro sufijo de pasado, -rqa, y que suele aparecer acompañado del reportativo $-\check{s i} /-s$, esta última interpretación es la más aceptada (Calvo 2008, Granda 1994).

En definitiva, la interpretación más extendida es que los dos valores mencionados de -sqa se han transferido a modo de calco al pretérito pluscuamperfecto del español, aunque cabría preguntarse si la miratividad se emplearía de la misma forma en las dos lenguas y por qué el calco se ha producido en el pluscuamperfecto. Blestel plantea una explicación al hecho de que se den usos muy similares en el pluscuamperfecto en el español en contacto con el quechua o con el guaraní, lengua que también codifica gramaticalmente la evidencialidad y la miratividad (véase Blestel 2011). La autora propone una convergencia lingüística mediante la cual se amplían las posibilidades de uso del pluscuamperfecto en español, que ya de por sí posee unas características modales y aspectuales que permiten la aparición de estos valores a partir de la lectura imperfectiva del auxiliar habia y el distanciamiento temporal en el eje cronológico al que apunta el pluscuamperfecto, interpretación con la que coincidimos en buena medida tras el análisis de los datos recogido en Chinchero que presentamos a continuación.

\section{EL ANÁLISIS DEL PRETÉRITO PLUSCUAMPERFECTO EN EL ESPAÑOL DE CHINCHERO}

\subsection{El CORPUS}

El corpus que analizamos en el presente estudio está formado por 17 entrevistas de 40 a 60 minutos de duración realizadas en dos trabajos de campo llevados a cabo en Chinchero en marzo de 2011 y septiembre de 2012. Las transcripciones han sido realizadas con el programa ELAN ${ }^{5} \mathrm{y}$ han sido revisadas por dos hispanohablantes nativos. El distrito de Chinchero, de

\footnotetext{
El software ELAN se encuentra disponible en http://tla.mpi.nl/tools/tla-tools/elan/, Max Planck Institute for Psycholinguistics, The Language Archive, Nijmegen, The Netherlands. Véase también: Wittenburg, P., Brugman, H., Russel, A., Klassmann, A., Sloetjes, H. 2006. ELAN: a Professional Framework for Multimodality Research. En Proceedings of LREC 2006, Fifth International Conference on Language Resources and Evaluation.
} 
$9.422^{6}$ habitantes, está situado a $28 \mathrm{~km}$ de la ciudad de Cuzco, y una de sus características principales es que la mayoría de sus habitantes son bilingües y tienen como lengua primera el quechua (de hecho, la investigadora no encontró ningún hablante monolingüe en español), en su vida diaria predomina el uso de ambas lenguas.

Todos los informantes entrevistados son bilingües, han nacido y han vivido siempre en Chinchero y la mayoría se dedica a la agricultura y/o la ganadería, o combinan estas actividades con otros trabajos en la municipalidad, en la escuela, en negocios de venta de artesanías y tejidos, etcétera. Se entrevistó a personas con diferentes características, los detalles y la subdivisión en función del género, la edad y el nivel socioeconómico (siguiendo la clasificación de Otheguy y Zentella 2012: 270-271) se pueden apreciar en la siguiente tabla.

Tabla 1. Distribución de los informantes

\begin{tabular}{|lll|}
\hline Género & Femenino & Masculino \\
Edad I (19-35 años) & 4 & 1 \\
Edad II (36-49 años) & 4 & 2 \\
Edad III (mayores de 50) & 3 & 3 \\
Nivel A (alto) & & \\
Nivel B (medio) & 3 & 5 \\
Nivel C (bajo) & 8 & 1 \\
\hline
\end{tabular}

La técnica de recopilación de datos fue la entrevista semidirigida que llevó a cabo la propia investigadora. En el protocolo se trataron temas relacionados con las costumbres y fiestas tradicionales, recetas de cocina, vida y ocupaciones cotidianas de los informantes, cambios en la comunidad en los últimos años, actitudes hacia el quechua y el español, así como la narración de leyendas tradicionales. En todos las entrevistas se procuró crear un ambiente de confianza, valiéndonos siempre de la ayuda de un mediador bilingüe quechua-español y también oriundo de Chinchero, y en algunos casos de la ayuda de vecinos de la localidad que se prestaron a colaborar en la investigación y que con su presencia contribuyeron a crear una comunicación más fluida con los informantes.

6 Datos del Instituto Nacional de Estadística e Informática de Perú (2007). 


\subsection{ANÁLISIS DEL CORPUS}

En total hemos recogido 53 ocurrencias de verbos en pretérito pluscuamperfecto; una primera visión de los datos nos llevó a corroborar que, al menos en las entrevistas semidirigidas en las que los informantes narran hechos destacables de su vida, el empleo con valor evidencial es el más usado en términos de frecuencia (el 92,4\% de los casos recogidos), lo que en contraste con la baja frecuencia de uso del pluscuamperfecto canónico con valor temporal-aspectual $(5,7 \%)$, pone de manifiesto la productividad en el discurso oral de este fenómeno. Aunque conviven los valores temporales y los modales en el uso del pluscuamperfecto sin problemas, parece que, al menos en el corpus analizado, los valores modales son ampliamente explotados y su desarrollo respondería a una necesidad comunicativa de expresar valores modales que sí se encuentran en la gramática del quechua. Por otra parte, el uso mirativo apenas aparece en una sola ocasión a lo largo de todas las entrevistas, lo cual era esperable, ya que está muy ligado a la conversación y las entrevistas realizadas, lejos de ser intercambios espontáneos, consistían en preguntas y respuestas largas en las que la entrevistadora no interrumpía prácticamente al entrevistado, lo cual no dejaba lugar apenas para la aparición de este tipo de exclamaciones mirativas.

Tabla 2. Usos del pluscuamperfecto en el corpus de español andino

\begin{tabular}{|l|l|l|}
\hline $\begin{array}{l}\text { Pluscuamperfecto con } \\
\text { valor canónico }\end{array}$ & $\begin{array}{l}\text { Pluscuamperfecto con } \\
\text { valor reportativo }\end{array}$ & $\begin{array}{l}\text { Pluscuamperfecto con } \\
\text { valor mirativo }\end{array}$ \\
\hline $3(5,7 \%)$ & $\mathbf{4 9 / 5 3 ( 9 2 , 4 \% )}$ & $1(1,9 \%)$ \\
\hline
\end{tabular}

Veamos los siguientes ejemplos representativos de los tres valores ${ }^{7}$. En primer lugar, presentamos un fragmento en el que el informante habla sobre los conocimientos de diversos fenómenos atmosféricos que tienen los habitantes de Chinchero, y expresa su convicción de que dichos saberes son ancestrales y no han sido aportados por los españoles y la cultura occidental, así pues, son anteriores, y para referirse a ellos emplea el pretérito pluscuamperfecto. Estamos así ante un ejemplo del uso canónico temporal-aspectual del pluscuamperfecto que señala a un punto anterior en la línea temporal:

7 En las transcripciones anotamos entre paréntesis el número de entrevista y el año en que fue realizada. Respecto a las personas que intervienen: $\mathrm{I}=$ Informante, $\mathrm{G}=\mathrm{Guía}$, $\mathrm{E}=$ Entrevistadora. 
Hay, cada año hay una, hay una temporada que creo que es agosto, no sé, septiembre, el espacio se... el sol comienza a formarse, eh... tiene esos escapes de los gases, el sol tienen, que tiene... Ellos habían conocido eso, conocieron ellos, inmediatamente tapan los manantes, y ese día no comen sus ganados. No comen porque dicen que, es que la, ese, ese gas ha envenenado a las plantas, la comida de los animales (10-2011).

En el segundo fragmento, en cambio, se observa un uso del pluscuamperfecto que nada tiene que ver con la anterioridad sino con información reportada, ya que la informante lo emplea para referirse a una información que no ha presenciado, por tanto que le ha sido transmitida a través de otras personas y de la que no está completamente segura. En dicho fragmento explica sobre la creencia de que en la laguna Piuray ${ }^{8}$ hay una sirena que a veces ha tirado hacia el fondo a niños y a otras personas descuidadas que se estaban bañando y que posteriormente no han sido encontradas. Después pasa a relatar el caso de una niña que soñaba que su mamá fallecida tiraba igualmente de la niña desde el fondo de la laguna en sus sueños, sueños que continúan hasta el momento actual, pues la niña ya es una mujer adulta. Al narrar esta historia lo hace con pretérito pluscuamperfecto, pues al referirse a esos hechos está hablando de una información que obviamente no ha presenciado porque se trata de los sueños de otra persona, sino que le ha sido transmitida. Nótese que su discurso está acompañado en varias ocasiones del marcador evidencial dice, que igualmente apunta a una información reportada ${ }^{9}$ :

E: ¿Se van a juntar las dos lagunas?

I: Se pueden juntarse dice, ajá. Por eso, los niños también casi no van a esa laguna, ya se murieron bastante, sí, le jala. Así por sí mismo te jala, es como un sirena, tiene su sirena.

E: ¿Sí? ¿Es peligrosa?

I: Peligrosa es, sirena tiene, digamos hace poco tengo una familia de aquí... entonces la niña se había dormido, unos diez años tiene esa niña, y se había dormido y bien dormida hasta las ocho de la noche.

8 La laguna Piuray es la laguna más grande e importante de Chinchero, de ella se extrae buena parte del agua que consume la ciudad de Cuzco. En torno a la laguna existen numerosas narraciones orales y leyendas que se han ido transmitiendo de generación en generación, así como relatos de fenómenos mágicos.

9 Sobre los valores del marcador dice en español andino, véase Zavala (2006). 
Entonce se había soñado que su mamá le está, estaba jalándole, "vamos, vamos", y así se iban volando y seguía, dice, hasta ahora sigue... (20-2011)

Por último, presentamos el único caso con valor mirativo que hemos registrado en el corpus. Durante la entrevista el informante saluda a un conocido que pasaba con su coche por allí, al darse la vuelta dicha persona y mirarlo con cara de extrañeza descubre que no se trata de su amigo y exclama:

¡Ah, no había sido él! ‘¡Ah, no es él!’ <creía que era mi amigo pero no es y me sorprende> (2-2012)

En este fragmento, por tanto, el hablante renuncia a sus expectativas pues se encuentra con una información nueva y desconocida que le sorprende, lo que codifica en español a través del pluscuamperfecto. Este uso mirativo presumimos que se utiliza con mayor frecuencia en la conversación cotidiana, pero en el corpus de entrevistas semidirigidas únicamente recogimos un ejemplo, como ya señalamos anteriormente.

En definitiva, el empleo que claramente predomina es el reportativo que se emplea para narrar hechos que están fuera del control del hablante y que no ha presenciado. Especialmente aparece en narraciones de leyendas o relatos de hechos que tienen que ver con lo mítico o legendario, esto es, cuando el narrador relata una historia cuya fuente o veracidad está fuera de control del narrador y que le ha sido transmitida a través de otras personas. Veamos a continuación el siguiente fragmento en el que una mujer narra una leyenda de Chinchero sobre la formación de la laguna Piuray. Según la leyenda, en el lugar donde se encuentra la laguna Piuray existía antiguamente la ciudad de Cuzco, un día se celebraba en esa ciudad un matrimonio de dos familias importantes, de pronto en el banquete entró un anciano con aspecto de pobre y los novios lo echaron de la fiesta, únicamente una cocinera se apiadó de él y le dio un poco de comida. En realidad el anciano era Dios y como castigo inundó la ciudad, pero antes avisó a la cocinera y le pidió que lo siguiera para salvarla, únicamente le advirtió que no mirara hacia atrás; sin embargo, la cocinera no pudo vencer su curiosidad, se dio la vuelta y se convirtió en piedra. Cerca de la laguna Piuray hay una piedra con la figura de una mujer que se dice que es la cocinera. Véase cómo todas la acciones de la narración de la leyenda se narran en pluscuamperfecto: 
(10) I: Había, dicen, un matrimonio graande. (CARRASPEO) El matrimonio, había [...]. Los novios, las novias, una familia, la comunidad, las visitas y todo, ¿no?

E: Mmh.

I: Entonce pasa queee, en esa comunidad aaah... Bueno era como una comunidad donde- que habían hecho una fiestaa y el...

E: Mmh.

I: Eeeh, dice quee unnn viejito pues, ¿no? Un viejito muuy muuy cochiniito bien suucio, dice, había entraado al matrimoonio, entons los novios habían dicho "Ay, no, ¿qué hace ese viejoo...? Suucio cochiino... Ese viejo que se vaya a bañar, ¿cómo va a venir a hacer...? Acá al matrimonio va a venir a hacer desorden, a hacer desesperar a la geente, está bien cochino y bien sucio, llévenselo."

E: Mmh...

I: La cocinera se había acerca((d))o, dice, le había limpiado la nariiiz, la cara, to((d))o limpio, ((lo)) había limpia((d))o y le había dado un porción de maíiiz, no sé si ((se)) lo había alcanzado... (7-2012)

Este uso se observa casi de forma sistemática cuando los informantes cuentan leyendas o narraciones orales, asimismo tienen en común que siempre aparecen acompañados del marcador reportativo dice, que igualmente señala una información transmitida o cuya fuente el hablante no puede asegurar. Detengámonos en el siguiente fragmento en el que otro informante narra igualmente la leyenda sobre la formación de la laguna Piuray; véase que el marcador dice aparece en siete ocasiones y que incluso se explicita la fuente de la información, en este caso la abuela de la informante:

(11) I: Mi abuelita dice que ahora esta laguna no era laguna sino era Cuzco... chiquito, pequeño, ajá, ciudad pequeño Cuzco era. Y había dice templos, casas, todo, era así entonces dice.

E: ¿Era la ciudad?

I: Sí. A un matrimonio un viejito creo que había entrado...(PERRO LADRANDO) a saludar, y esa señora, los que se han casado... a una casa que se han matrimoniado había entrado un viejito, y le habían... habían tenido asco porque estaba el abuelito con su moco así todo cochinito, entonce habían tenido asco, entonces de ahí dice una señora lo había limpiado, ¿no?, al abuelito. Entonces a esa señora le había dicho: "Anda, hijita al cerro, anda, pero no te vas a mirarte a tu detrás porque... no te vas a mirar, sin mirar te 
vas irte". Y la señora dice que se fue al cerro ahí, dice cuando del cerro volteó miró atrás entonce la laguna estaba creciendo, a las casas así estaba tragando, entonces así en ahí la señora dice que se ha encantado, piedra había, ahí había.

E: ¿Ah sí?

I: Sí, hay una señora con... con su pushka así está, está hilando, ahí se había encantado y así. (19-2012)

Además de este valor reportativo de las narraciones orales, en otros casos el uso del pluscuamperfecto parece apuntar a una evaluación de la veracidad de la información por parte del hablante, esto es, a través del uso del pluscuamperfecto el narrador se distancia de la información, implicando así duda o incertidumbre sobre la misma. Véase el siguiente ejemplo en el que el hablante cuenta sobre un terrateniente que vivía en Chinchero hace más de 30 años y que era conocido por su trato abusivo sobre la mano de obra que trabajaba en su finca. En un determinado momento de la narración el hablante cuenta que abusaba de las trabajadoras y que algunas quedaron embarazadas de él. Que abusaba de las mujeres parece que era algo sabido por todos, pero que algunos de los hijos de las mismas eran de él, además de ser una información delicada no es totalmente segura, ya que posiblemente las mujeres no hicieron público que su hijo era fruto de una violación del patrón de la finca donde trabajaban, más bien se trata de rumores o comentarios que se cuentan en la comunidad. Parece incluso que sería un tema tabú, ya que el hablante da varios rodeos y duda sobre cómo referirse a ello. Primero va describiendo con imperfectos cómo era esa persona y únicamente para señalar esa información no complemente veraz o fiable, que algunos de los hijos de esas mujeres eran suyos, el hablante emplea el pluscuamperfecto:

(12) I: Es así, ¿verdad? Cómo maltrataba a la gente...

E: Ya, ya, ya, ya...

I: No sé pero... Totalmente... Por ejemplo dos, este, señoras, estee... E: Sí...

I: No sé, ((a cierto mal)) lo hacía quedar la mujer. Ps así, estee, hasta incluso había... había tenido hijos así, fuera del matrimonio. Y la abusaba...

E: Sí...

I: Quince años, nada, qui- nada, nada, ((nadies)). Como no había justicia... Sí es, ah, total atroz Chinchero. Sí. (3-2012) 
En este caso, aunque es evidente que el hablante está transmitiendo una información reportada, no utiliza el marcador dice como sería esperable, sino que parece que el pluscuamperfecto desempeña una función de validación de la información. Así, interpretamos que el hablante no activa siempre la lectura reportativa, sino que evalúa la información como no completamente cierta o fiable y se distancia de ella, pues no se puede comprometer con la veracidad de la misma, lo que codifica gramaticalmente a través del empleo del pluscuamperfecto. Esto supone que la evaluación de la veracidad de la información es lo que hace que el hablante active el uso del pluscuamperfecto, no la evidencialidad, pues en muchos otros casos en los que se refieren a hechos no experimentados no utilizan el pluscuamperfecto para referirse a ellos. Interpretamos pues que el pluscuamperfecto puede señalar evidencialidad en el sentido más estricto al narrar leyendas como la citada anteriormente, lo que además aparece acompañado de dice, pero no es el factor clave o no al menos el único que determina la presencia del mismo, sino que más bien los hablantes lo emplean para estas narraciones por tratarse de una información no confiable, y refuerzan su distanciamiento mediante el marcador reportativo dice. Así, no obligatoriamente usan el pluscuamperfecto siempre para las leyendas, como se puede apreciar en los ejemplos de (13) que están narrados con indefinidos e imperfectos, sino que es la evaluación subjetiva del hablante la que determina la activación de este recurso. Así pues, el análisis parece apuntar más bien a que el empleo de dice o de otros verbos dicere (dicen, me han contado...) es el que señala la información reportada ${ }^{10}$ :

(13) a. I: Acá tienen leyenda, por ejemplo esa laguna de Piuray que ustedes- hemos visto, para ellos es una ciudad de sus antepasados que era- dice que la laguna es una inundación y lo tapó a la ciudad, entonces dentro de esa leyenda dicen así, ¿no?, que una persona anciana con bigotes, todo sucio, sin ropa, todo, entró a un, en un matrimonio en medio de la ciudad el hija del cacique que se casaba, y no le dieron una comidita como debe ser, entonces lo botaron más bien por tener asco al hombre, al viejito, entonces esa... Como lo botaron se regresó y la cocinera, que cocinaba, lo trajo comidita: "Señor, cómase esto", el viejito dijo: "Sígueme". Y se fue por las

\footnotetext{
10 Nótese que se utiliza el pretérito perfecto para narrar hechos perfectivos, el valor tanto de pretérito perfecto como indefinido también presentan innovaciones en el español andino peruano; véase Klee y Ocampo (1995) o Escobar (1997).
} 
alturas, y le dijo: "No mires atrás. Mira delante no más. Atrás me sigues".

E: Sí.

I: Pero la cocinera miró y se encantó, dice... (10-2011)

b. Y... antes no había una laguna dicen, así según que me han contao, que no era laguna, había una fiesta acá en la... hay un sitio dice que se llamaba [...], abajo ahí hay un sitio y entonce una fiesta hacían ¿no?, lo que es matrimonio, todo estaba realizándose en esa fiesta. Entonces un... un viejito llegó ¿no?, de viaje, con un moco, no todo de... sus ropas eran destrozado, todo... Y entonces una señora, por compasión, ¿no?, decía: (HABLA EN QUECHUA), le ha invitao, ¿no?, y la señora le ha dicho que "señora, tienes que ir a, por, por detrás del muro por ahí no más tienes que seguir así no más, tienes que ir no más. Y verdad pué la señora obedeció, dice, entonce siguió, entonces por casualidad la señora se volteó y se ha convertido la laguna, esta laguna. Entonces ese, lo que dicen, llamamos ese sitio, se llama... ((Payajquiro)). Ahí una señora está con, con... de piedra es, debías, podríamos ir a ver, arriba está. Entonces se volteó y se convirtió en una laguna, ajá, posiblemente que era, dice que era Cristo ha venido y nadie se... eh... ni se darán cuenta, ¿no? (15-2011)

De esta forma, cuando el hablante subjetivamente evalúa la información que transmite como no totalmente veraz o fiable emplea el pluscuamperfecto. Veamos, por último, otro ejemplo en el fragmento citado en (14):

(14) I: Sí, porquee al menos Chinchero era muy atrasadísimo. Ahora ha crecido la población...Yyy así pues, estee, sus propios hijos chincherinosss [es] tán tratando de avanzar, ¿no?

E: Mmh.

I: [...] Ahora... antes, autoridades de Chinchero ha-habían sido unos explotadores.

E: Aah...

I: Queee eran los blancos y los campesinos eran para ellos ((nomás)), eran unos ((chombos)).Yyy... pues, estee... lo manejaban, ¿no? Porque por ((aquí)) quitaban los terrenos, por ejemplo esta zona donde está caminando usted... casi lo convierten en una hacienda, un tal terrateniente que era... que había sido Álvarez, familia 
Álvarez... Menos mal, (ahora) UNA familia nomás está viviendo, el resto... se ha ido, sí. (3-2012)

En el mismo, el hablante habla sobre los terratenientes anteriores a la reforma agraria llevada a cabo en los años 60 y se refiere a ellos como "explotadores", pero no es una información de la que está completamente seguro, pues no vivió ese proceso ni lo conoce con exactitud, por ello activa el uso del pluscuamperfecto. Asismismo, cuando se refiere a uno de los terrratenientes de cuyo nombre duda pues no está seguro de recordarlo bien, igualmente lo marca con pluscuamperfecto.

\section{DISCUSIÓN: UN CAMBIO INDUCIDO POR CONTACTO}

Que el contacto con el quechua está detrás del fenómeno analizado en esta variedad parece claro, aunque se hace necesario explicar el proceso mediante el cual se ha producido la asunción de valores evidenciales y mirativos por parte del pluscuamperfecto, esto es, de qué forma se ha producido la influencia del quechua en la gramática del español. Pasemos pues, en primer lugar, a examinar las características del quechua que podrían estar motivando el cambio descrito.

Como hemos señalado anteriormente, en quechua existen dos sufijos que marcan los verbos en pasado pero que establecen una diferenciación semántica importante:

-r(q)a: se utiliza para señalar un hecho puntual en el pasado y para señalar eventos del pasado sin otro significado añadido.

-sqa: se emplea para narrar hechos no vividos o realizados sin control por parte del hablante, por ejemplo, en sueños o en otra circunstancia que haga imposible su conocimiento directo, por ejemplo, que sean datos transmitidos mediante narraciones orales; igualmente se usa como sorpresivo para comunicar que un evento o información es inesperado o produce sorpresa en el hablante y lo acaba de descubrir. 
Para la variante de quechua $\mathrm{B}$ o quechua $\mathrm{II}^{11}$, hablada en el centro y norte de Perú, contamos con el estudio de Hintz (2007) relizado en Conchucos, donde observa que -sh $((q) a)$ ha perdido sus valores evidenciales y se encuentra en un proceso de gramaticalización en el que se van desdibujando los valores reportativos y, además de sorpresivo, se explota en el discurso oral para narrar eventos como un pasado no marcado. Según la autora, se utiliza con este valor especialmente en combinación con - rqa que marca el inicio y el desenlace de la narración, y de esta forma orienta al oyente hacia el tópico y desenlace del discurso.

No obstante, en el quechua A o quechua I, hablado en Ecuador, Bolivia, noroeste de Argentina, y más concretamente en el quechua del sur de Perú que nos ocupa, -sqa parece no haber perdido el sentido evidencial y es empleado para hablar de un evento que el hablante sabe a través de otra/s persona/s, pero que no ha experimentado o presenciado, como en el siguiente ejemplo ${ }^{12}$ :

\section{Pomacanchipis ukukukuna tususqaku.}

'Dice(n) que en Pomacanchis habían bailado los ukukus' < lo sé porque me lo han contado, no lo he presenciado>.

Asimismo, -sqa es ampliamente usado no únicamente para referirse a la noción pura de evidencialidad en el sentido de que el hablante no ha presenciado los hechos, sino que se explota pragmática y discursivamente para referirse a una información que ha sido realizada fuera del control del hablante, de modo que no puede asegurar la veracidad de los mismos. Por esta razón y no estrictamente por la exigencia de que el hablante haya presenciado los hechos, en muchas ocasiones es empleado para narrar eventos míticos o leyendas transmitidas oralmente, por lo que este sufijo es llamado también "narrativo" o "delegatorio". Como señala Cerrón-Palomino (1987) en las variantes sureñas y centrales de quechua -sqa indica:

[...] una acción ejecutada sin control por parte del hablante (durante un sueño, por ejemplo), o puede indicar asimismo una actitud de sorpresa por parte de quien describe el hecho. Dicho sufijo que es empleado predominantemente en los relatos (motivo por el cual se le llama

\footnotetext{
11 Sobre las clasificaciones de las variantes del quechua, véase Adelaar (2013).

12 Quiero agradecer a Janett Vengoa de Orós, mediadora intercultural, profesora y traductora de quechua, su valiosa y desinteresada colaboración en mi investigación con sus comentarios, así como con los ejemplos en quechua (de la variante del sur de Perú), la traducción al castellano y la interpretación de los datos recogidos en las entrevistas.
} 
tradicionalmente "pasado narrativo"), se da como - ñaq (o variantes) en los dialectos del QI $I^{13}$ y como -šqa (y variantes) en los demás. (CerrónPalomino 1987: 273)

Así, puede emplearse para hablar de hechos soñados o de los que el hablante no era consciente. Véanse los siguientes ejemplos en los que se usa $-s q a$ para hablar de eventos ocurridos cuando la hablante era muy pequeña y por tanto inconsciente de lo que ocurría a su alrededor; nótese que los hechos le han sido transmitidos por otras personas, pues es incapaz de recordarlos en la edad adulta ${ }^{14}$ :

(16) a. Wawacha kaqtiy unuchawasqaku.

'Cuando era recién nacida me habían bautizado.'

b. Unuchakuyniypi askhata kusikusqani.

'En mi bautizo me habían puesto ropa blanca.'

c. Watachaypi askhata kusikusqani.

'En mi fiesta de un añito me había alegrado mucho.'

Por otra parte, en todas las variantes de quechua el sufijo evidencial -sqa también expresa sorpresa; en lenguas en las que está gramaticalizada la evidencialidad, es frecuente que estas marcas se empleen igualmente para expresar miratividad, pues de la codificación de la falta de participación en el evento y la falta de acceso a la fuente pueden derivar construcciones que expresan que la información no era esperada por el hablante y que el conocimiento de la misma es nuevo (Aikhenvald 2004). Asimismo, esto vendría a fortalecer la interpretación de los usos mirativos del pluscuamperfecto en español en relación con este sufijo verbal:

a. Chayamusqankitaq.

'¡Ya habías llegado! <y me sorprende>'

b. Tutachallamantan taytay chayamusqa.

'Tempranito había llegado mi papá <y me sorprende>'

Cabe señalar, por último, que en línea con Cerrón Palomino (1987) o Adelaar (1997), creemos que el sufijo - sqa, así como los otros marcadores de evidencialidad y validación no están sujetos al sentido estricto evidencial

Variedades de la sierra norteña y central de Perú.

Ver nota 12. 
de realidad experimentada y observada, sino que más bien funcionan como validadores que codifican la evaluación subjetiva del hablante sobre la veracidad de la información y la fiabilidad de la fuente, así como de su distanciamiento frente al evento narrado, razón por la cual es empleado con frecuencia para contar leyendas o hechos que están fuera del control del hablante y, por tanto, de su realidad, como sueños, hechos de cuando son bebés, etc.; así como para expresar miratividad, pues el hablante trata de distanciarse de un hecho pasado que no responde a sus expectativas ya que acaba de descubrir que no sucedió como imaginaba.

El paralelismo entre el valor de sufijo $-s q a$ y el pluscuamperfecto en español andino resulta significativo; no obstante, como señala acertadamente Blestel, la interpretación de estos usos como un calco semántico "no deja de plantear problemas, pues si el pluscuamperfecto ha cambiado de 'valor', entonces estaríamos ante una reestructuración completa del sistema verbal, pues el conjunto de formas (imperfecto, pasado compuesto, etc.) tendría que reorganizarse en función de este cambio" (Blestel 2011: 74). Pues ambos usos, el canónico y el innovador que implica valores mirativos y evidenciales, conviven en las variedades andinas y paraguaya, e igualmente lo hemos observado en nuestro corpus. Además de la hipótesis del calco, se han planteado diversas interpretaciones sobre este fenómeno y el mecanismo por el que estos usos se han desarrollado a través del pluscuamperfecto. Por ejemplo, Escobar (1997) propone la asunción de estos valores modales o epistémicos como un paso más en el proceso de gramaticalización del pluscuamperfecto que podría desarrollar un significado epistémico y acercarse a un subjuntivo, de la misma forma que ocurrió con el subjuntivo imperfecto (-ra) derivado del pluscuamperfecto latino. No obstante, quedaría por aclarar de qué forma ha influido el quechua en la identificación del pluscuamperfecto con la evidencialidad o la miratividad.

Blestel (2011) y Speranza (2010) explican este fenómeno por la potencialidad que el significado del pluscuamperfecto posee en español, interpretación con la que coincidimos, como trataremos de demostrar a continuación. El auxiliar haber en imperfecto (había) denota un estado focalizado imperfectivamente y dota al pluscuamperfecto de cierto carácter imperfectivo, lo que unido a su significado de anterioridad hace que remita "al plano de 'lo inconcluso' y, por lo mismo, de 'lo desconocido', de lo incierto, de lo remoto" (Speranza 2010: 94). Sobre este aspecto igualmente Cartagena afirma que aunque el significado básico del pluscuamperfecto tiene carácter perfectivo referido al pasado, "normalmente expresa un periodo indefinido o, por lo menos, claramente perceptible. Es decir, es un tiempo que se presta especialmente para indicar larga duración o repetición de acciones anteriores a un momento pasado" (Cartagena 1999: 2954). De 
esta forma, el hablante se distancia del hecho de que ya está terminado y no forma parte de su experiencia presente, pero que además se sitúa en un periodo de tiempo indefinido y desvinculado igualmente del momento actual. Por ello, el pluscuamperfecto se constituye como un excelente recurso para referirse a un hecho pasado que no se ha conocido de primera mano ni se ha podido experimentar, y es el espacio perfecto mediante el cual codificar la evidencialidad. De hecho, se ha descrito que con frecuencia el perfecto y el evidencial comparten un origen diacrónico en estructuras resultativas de origen estativo, y que en lenguas que no gramaticalizan la evidencialidad es frecuente usar el perfecto como recurso para expresarla, tanto por propia evolución interna como por situaciones de contacto con otras lenguas, como se observa en español andino (Aikhenvald 2004, Bermúdez 2005), pues su evolución se fundamenta en una base semántico-pragmática común a los sistemas de perfecto, evidencial y mirativo relacionada con la subjetividad epistémica y la vinculación del hablante con el evento que está narrando (Soto y Hasler 2013).

Igualmente para el valor el sorpresivo, el hablante renuncia y se distancia de sus expectativas de lo que había creído como información cierta y marca su sorpresa mediante el pluscuamperfecto; el proceso cognitivo es similar al de validación de la información y realmente, como afirma Blestel (2011: 78), "solo la enunciación permite al interlocutor entender que ese había sido ha de ser entendido como admirativo". De hecho, en variantes de español que no están en contacto con otras lenguas se han registrado usos modales o sorpresivos igualmente, aunque con restricciones específicas ${ }^{15}$. En el español chileno Soto y Olguín (2010) interpretan el giro ;No se me había ocurrido nunca! como un pluscuamperfecto con valor mirativo y señalan que este tiempo por su estructura temporal se presta para expresar este significado. De la misma forma, en español andino en ejemplos como (3b) o (9), al decir el hablante jno habias sido mujer! o ino había sido él!, se está distanciando y sitúa dicho evento fuera de su experiencia o conocimiento presente, lo aleja o se desvincula de la misma pues está fuera de sus expectativas.

Así, el uso de valores evidenciales y validadores responde a la libertad del hablante para jugar con los distintos significados del lenguaje y adecuarlos a sus necesidades comunicativas, agregando además un elemento subjetivo de evaluación de veracidad de la información o de la fuente de datos sobre la información que se quiere transmitir, y desvinculándose de ella

\footnotetext{
15 Relacionadas con el tipo de predicado, el tipo de predicado, la polaridad negativa y la necesidad de estar en una oración exclamativa.
} 
si subjetivamente lo cree necesario. Se explotan así las posibilidades que ofrece el sistema gramatical del español y, aunque están muy cerca de los significados descritos para el quechua, creemos que los valores evidenciales y validadores se han introducido a través del pluscuamperfecto, pues de por sí en español es susceptible de expresar validación o sorpresa así como ubicación en un pasado anterior y terminado, en un periodo algo difuso que está desvinculado de la experiencia presente.

Postulamos entonces que se ha producido un cambio lingüístico inducido por contacto, mediante el cual el pluscuamperfecto ha ampliado las posibilidades de expresar miratividad y ha adquirido valores relacionados con la evidencialidad y la validación, que permiten así codificar si un hecho ha sido visto o experimentado, si subjetivamente se considera veraz o está fuera del control o el conocimiento del hablante por diversas razones. Creemos pues que no se trata de un mero calco semántico, sino de una explotación de posibilidades que el español ya posee, pero cuyo disparador ha sido el contacto con el quechua, pues no se han registrado usos con características similares en otras variedades de castellano que no estén en contacto con otras lenguas ${ }^{16}$. Proponemos así que el mecanismo para que se produzca el cambio es un proceso cognitivo en el que los hablantes bilingües perciben semejanzas (siguiendo a Jarvis y Pavlenko 2008) en un recurso de la gramática quechua para expresar evidencialidad y miratividad, el sufijo $-s q a$, con los significados modales que puede expresar el pluscuamperfecto en español así como de distanciamiento en el eje cronológico y de imperfectividad, y se dispara el cambio que desemboca en la ampliación de usos mirativos y la adopción de valores evidenciales por parte del pluscuamperfecto. Ello implica asimismo un aumento en su frecuencia de uso, pues resulta de la puesta en marcha de estrategias comunicativas que los hablantes bilingües ya tienen en su lengua primera y se constituye como un recurso altamente productivo en la segunda. En definitiva, las estrategias que se ponen en marcha tienen que ver con la necesidad de cubrir necesidades comunicativas de los hablantes a partir de los recursos coherentes que perciben en su segunda lengua.

16 Únicamente en el español chileno se han registrado casos con valor mirativo pero con muchas restricciones (Soto y Olguín 2010). 


\section{CONCLUSIONES}

A lo largo de este trabajo hemos pretendido dar cuenta no solo de un cambio emergente del español andino, sino del proceso que ha llevado a ese estado de lengua y los principios que lo rigen. Hemos tratado de evaluar el impacto de la situación de contacto con el quechua, el factor externo que desencadena el cambio, y los mecanismos mediante los cuales se ha producido la adopción de nuevos significados modales relacionados con la evidencialidad y la miratividad en el pretérito pluscuamperfecto del español. Postulamos así que estos nuevos significados son producto de un cambio inducido por contacto con el quechua, resultado de un proceso cognitivo en el que el hablante bilingüe percibe similitudes en determinadas áreas de sus dos lenguas y explota determinados recursos o estrategias comunicativas de su primera lengua en la segunda. Este proceso desemboca en un cambio semántico que implica un aumento de su frecuencia de uso y una reducción de las restricciones en los usos mirativos del pluscuamperfecto, así como en la adopción de usos modales en el mismo mediante los cuales el hablante evalúa subjetivamente la fiabilidad de la fuente de información, así como la veracidad de la misma.

Estamos ante un cambio emergente que no parece ser un error de aprendizaje de español como segunda lengua, pues está generalizado en la variedad estudiada e igualmente ha sido detectado en otras variedades de contacto con el quechua o el guaraní; por tanto estamos ante procesos generales de cambio en español en contacto con otras lenguas que por una parte se desencadenan a partir de la influencia de la lengua de contacto, pero que también explotan posibilidades ya existentes en español, como la de expresar usos modales mediante los tiempos de perfecto. Así, entran en juego factores internos de cambio en la lengua, pero también la necesidad de codificar valores que no están gramaticalizados en español, que emergen en aquellas áreas de la gramática que permiten o que mejor pueden expresar esos significados. Los hablantes que no poseen los mecanismos gramaticales con los que indicar las fuentes de la evidencialidad resuelven sus necesidades comunicativas generando estrategias con las que dan cuenta del fenómeno, activan estas formas en su discurso y las utilizan como alternativas a las no marcadas, explotando así estrategias comunicativas del quechua que el español no tiene.

Queremos destacar, por último, que el español andino tiene una lógica interna y los cambios inducidos por contacto observados en el mismo, como el caso de los usos evidenciales y mirativos del pluscuamperfecto, persiguen 
una mayor claridad y transparencia en el mensaje que se quiere transmitir; en definitiva, cubrir determinadas necesidades comunicativas de los hablantes.

\section{REFERENCIAS BIBLIOGRÁFICAS}

Adelaar, Willem. 1997. Los marcadores de validación y evidencialidad en quechua: ¿automatismo o elemento expresivo? Amerindia 22: 3-13.

2013. Quechua I y Quechua II: En defensa de una distinción establecida. Revista Brasileira de Linguística Antropológica 5(1): 45-65.

Aikhenvald, Alexandra. 2004. Evidentiality. Oxford: Oxford University Press.

Bermúdez Wachtmeister, Fernando. 2005. Evidencialidad: La codificación lingüistica del punto de vista. Tesis para optar al grado de Doctor en Lingüística Hispánica. Estocolmo: Universidad de Estocolmo.

Blestel. Elodie. 2011. El pluscuamperfecto de indicativo en contacto con tres lenguas amerindias. Lenguas Modernas 38: 63-82.

Calvo, Julio. 2008. Perú. En Palacios, A. (coord.). El español en América. Contactos lingüísticos en Hispanoamérica. Barcelona: Ariel, pp. 189-212.

Cartagena, Nelson. 1999. Los tiempos compuestos. En Bosque, I. y V. Demonte (coords.). Gramática Descriptiva de la Lengua Española. Madrid: Espasa Calpe, pp. 2935-2975.

Cerrón-Palomino, Rodolfo. 1987. Lingüistica quechua. Cuzco: Centro de Estudios Regionales Andinos Bartolomé de las Casas.

Cusinuamán, Antonio. 1976. Gramática quechua, Cuzco-Collao. Lima: Ministerio de Educación.

DeLancey, Scott. 2001. The mirative and evidentiality. Journal of Pragmatics 33: 369-382.

Dendale, Patrick y Lilianae Tasmowski. 2001. Introduction: Evidentiality and related notions. Journal of Pragmatics 33: 339-348.

Escobar, Anna María. 1997. Contrastive and Innovative Uses of the Present Perfect and the Preterite in Spanish in Contact with Quechua. Hispania 80: 859-870.

2011. Spanish in Contact with Quechua. En Díaz-Campos, M. (ed.). The Handbook of Spanish Sociolinguistics. Oxford: Wiley-Blackwell, pp. 323-352.

Faller, Martina. 2003. The Evidential and Validational Licensing Conditions fot the Cusco Quechua Enclitic - mi.Belgian Journal of Linguistics 16, 7-21.

2007. The Cusco Quechua Reportative Evidential and Rhetorical Relations. Linguistische Berichte Sonderheft Special Issue on Endangered Languages 14: 223-251.

García Fernández, Luis. 2008. Pretérito pluscuamperfecto y pretérito anterior. En Carrasco Gutiérrez, A. (ed.). Tiempos compuestos y formas verbales complejas. Madrid/Frankfurt: Iberoamericana/Vervuert, pp. 359-400

García Tesoro, Ana Isabel. 2013. El español de los Andes: ¿variedad estable o "español bilingüe"? Perspectivas latinoamericanas 10. Nagoya: Center for Latin American Studies, Nanzan University, 115-131.

2014. Construcciones causativas en español andino. Estudios Lingüísticos Hispanos 29, Tokio: Universidad de Estudios Extranjeros de Tokio: 25-46.

Godenzzi, Juan Carlos. 1996. Transferencias lingüísticas entre el quechua y el español. Signo y Seña 6: 73-99. 
GRANDA, GeRmÁn DE. 1994. Dos procesos de transferencia gramatical de lenguas amerindias (quechua/aru y guaraní) al español andino y al español paraguayo. Los elementos validadores. Revista de Filología Hispánica LXXIV 1(2): 127-141.

Haboud, Marleen. 1998. Quichua y castellano en los Andes Ecuatorianos: los efectos de un contacto prolongado. Quito: Abya-Yala.

HintZ, DANiel. 2007. Duplicación de patrones discursivos: Empleo del perfecto en el castellano que está en contacto con el quechua. Ponencia presentada en el $V$ Congreso Nacional de Investigaciones Lingüístico-Filológicas, University of California, 8-10 de agosto.

Jara, Margarita. 2011. Funciones discursivas y gramaticalización del pretérito perfecto compuesto en el español de Lima. Spanish in Context 8:1: 95-118-

Jarvis Scott y Aneta Pavlenko. 2008. Crosslinguistic Influence in Language and Cognition. New York: Routledge.

Klee, Carol y Andrew Lynch. 2009. El español en contacto con otras lenguas. Washington: Georgetown University Press, pp. 113-168.

Klee, Carol y Alicia M. Ocampo. 1995. The Expression of Past Reference in Spanish Narratives of Spanish-Quechua Bilingual Speakers. En Silva-Corvalán, C. (ed.). Spanish in Four Continents: Studies in Language Contact and Bilingualism. Washington D.C.: Georgetown University Press, pp. 52-70.

Manley, Marilyn 2007. Cross-linguistic influence of the Cuzco epistemic system on Andean Spanish. En Potowski, K. y R. Cameron (eds.). Spanish in Contact: Policy, social and linguistic inquiries. Amsterdam/Philadelphia: John Benjamins, pp. 191-209.

Mendoza, J. G. 2008. Bolivia. En Palacios, A. (coord.). El español en América. Contactos lingüisticos en Hispanoamérica. Barcelona: Ariel, pp. 213-236.

Merma Molina, Gladys. 2008. El contacto lingüistico en el español andino peruano. Estudios pragmático-cognitivos. Alicante: Universidad de Alicante.

Otheguy, Ricardo y Ana Celia Zentella. 2012. Spanish in New York. Language contact, dialectal leveling, and structural continuity. Oxford/New York: Oxford University Press.

Palacios, Azucena. 2008. Paraguay. En Palacios, A. (coord.). El español en América. Contactos lingüísticos en Hispanoamérica. Barcelona: Ariel, 279-300.

2013. Contact-induced Change and Internal Evolution: Spanish in Contact with Amerindian Languages. En Léglise, I. y C. Chamoreau (eds.). The Interplay of Variation and Change in Contact Settings. Morphosyntactic Studies. Amsterdam/Philadelphia: John Benjamins (Studies in Language Variation), pp. 165-198.

Palacios, Azucena y Ana Isabel García. 2014. Relevancia informativa y foco discursivo en español andino: estructuras de ya duplicado. Actas del Congreso Internacional sobre el español y la cultura hispánica. Instituto Cervantes de Tokio (2013), http://cvc.cervantes. es/ensenanza/biblioteca_ele/publicaciones_centros/tokio_2013.htm, pp. 162-180.

Palacios, Azucena y Stefan Pfänder. 2014. Similarity effects in language contact: Taking the speakers' perceptions of congruence seriously. En Besters-Dilger, J., C. Dermarkar, S. Pfänder y A. Rabus (eds.). Congruence in Contact-induced Language Change. Language Families, Typological Resemblance, and Perceived Similarity. Berlin/New York: Mouton de Gruyter (Linguae \& Litterae), pp. 219-228.

Palmer, Frank. 1986. Mood and modality. Cambridge: Cambridge University Press.

Pfänder, Stefan. 2009. Presencia del quechua en el castellano boliviano, vol. II. Gramática mestiza. Con referencia al Castellano de Cochabamba. La Paz: Instituto Boliviano de Lexicografía y otros Estudios Lingüísticos.

Pfänder Stefan y Azucena Palacios. 2013. Evidencialidad y validación en los pretéritos del español andino peruano. Círculo de Lingüistica Aplicada a la Comunicación 54: 65-98. 
Soto, Guillermo y Felipe Hasler. 2013. Perfecto, antiperfecto, evidencial y admirativo: decir un evento para comunicar dos. Círculo de Lingüística Aplicada a la Comunicación 54: $130-153$.

Soto, Guillermo y Nicolás Olguín. 2010. ¡No se me había ocurrido nunca! Una construcción admirativa del pluscuamperfecto en español. Onomázein 22(2): 83-105.

Speranza, Adriana. 2010. Estrategias discursivas en la transmisión de la información: el español en contacto con lenguas americanas. Revista Internacional de Lingüistica Iberoamericana (RILI) 15(1): 89-105.

Traugott, Elizabeth Closs. 1989. On the rise of epistemic meanings in English: an example of subjectification in semantic change. Language 65: 31-55.

1995. Subjectification and grammaticalization. En Stein, D. y S. Wright (eds.). Subjectivity and subjectivisation. Cambridge: Cambridge University Press, pp. 37-54.

Zavala, Virginia. 1996. El Castellano de la Sierra de Perú. En Tomoeda, H. y L. Millones (eds.). La Tradición Andina en Tiempos Modernos. Osaka: National Museum of Ethnology, pp. 81-131.

2006. Transferencia de funciones evidenciales del quechua: El rol de pues como marcador discursivo en el español andino. Lexis 30(1): 55-82. 